\title{
ON SOME ABSTRACT CONVEXITY NOTIONS IN REAL LINEAR SPACES
}

\author{
RADU IOAN Boţ, ERNÖ RoBERT CSETnEK AND GERT WANKA
}

\begin{abstract}
We introduce some abstract convexity notions in a real linear space and investigate which of the results from the convex analysis in topological vector spaces still work in a linear space. The differences between these abstract convexity notions and those established in spaces endowed with a topology are underlined by some examples.
\end{abstract}

Mathematics subject classification (2000): 15A03, 52A01, 52A41.

Key words and phrases: abstract convexity, c-convex hull, c-convexity.

\section{REFERENCES}

[1] DOLECKI, S., KURCYUSZ, S. (1978): On $\phi$-convexity in extremal problems, SIAM Journal on Control and Optimization 16, 277-300.

[2] Ekeland, I., Temam, R. (1976): Convex analysis and variational problems, North-Holland Publishing Company, Amsterdam.

[3] ElSTER, K.H., NeHSE, R., (1974): Zum Dualitätssatz von Fenchel, Mathematische Operationsforschung und Statistik 5, Vol. 4/5, 269-280.

[4] ERnSt, E., THÉRA, M., VOLLE, M. (2006): Self-equilibrating sets and functions in dual vector spaces: two boundedness criteria, Rapport de Recherche $\mathrm{N}^{\circ}$ 1, Université de Limoges.

[5] Holmes, R.B. (1975): Geometric functional analysis, Springer-Verlag, Berlin.

[6] KutateladZe, S.S., Rubinov, A.M. (1972): Minkowski duality and its applications, Russian Mathematical Surveys 27(3), 137-1972.

[7] MartineZ-LegAZ, J.E., SingeR, I. (1998): On $\phi$-convexity of convex functions, Linear Algebra and Its Applications, 278, 163-181.

[8] Pedersen, G.K. (1989): Analysis now, Graduate Texts in Mathematics, 118, Springer-Verlag, New York.

[9] PINI, R., SINGH, C. (1997): A survey of recent [1985-1995] advances in generalized convexity with applications to duality theory and optimal conditions, Optimization 39, 311-360.

[10] Rockafellar, R.T. (1970): Convex analysis, Princeton University Press, Princeton.

[11] RolewicZ, S. (2001): Open problems in $\Phi$-convexity. Unsolved Problems on Mathematics for the 21st Century, 101-108, IOS, Amsterdam.

[12] Rubinov, A.M. (2000): Abstract convexity and global optimization, Nonconvex Optimization and Its Applications 44, Kluwer Academic Publishers.

[13] SingeR, I. (1997): Abstract convex analysis, John Wiley, New York.

[14] Soltan, V.P. (1984): Introduction to axiomatic theory of convexity (in Russian), Stiinca, Kishiniev.

[15] ZăLINESCU, C. (2002): Convex analysis in general vector spaces, World Scientific, Singapore. 